\title{
Sobre a publicação eletrônica na plataforma SEER - Sistema Eletrônico de Editoração de Revistas
}

\author{
Diego Abadan \\ diego@lepidus.com.br \\ Lepidus Tecnologia \\ Periódicos em Nuvens
}

DOI: http://dx.doi.org/10.7322/abcshs.v38i3.16

A ABCS Health Sciences, em busca do aperfeiçoamento para atender aos mais altos padrões de qualidade, passa a adotar, a partir desta edição, uma plataforma especializada para o gerenciamento e a publicação eletrônica de revistas científicas pela web: a Plataforma SEER.

A plataforma SEER, acrônimo de Sistema Eletrônico de Editoração de Revistas, é desenvolvida no âmbito da Public Knowledge Project (PKP), uma iniciativa de universidades internacionais com o objetivo de investir em pesquisa e desenvolvimento de softwares livres para a melhoria da qualidade e do alcance de publicações acadêmicas.

No Brasil, o uso da plataforma SEER é fomentado pelo Instituto Brasileiro de Informação em Ciência e Tecnologia (IBICT), um dos principais responsáveis pela rápida adoção desta plataforma no país. Recomendada pela CAPES para a publicação de revistas científicas e amplamente aceita pela comunidade acadêmica brasileira, é utilizada por revistas de todo porte e em muitas partes do mundo para o gerenciamento de suas publicações.

Diversas instituições de ensino e pesquisa brasileiras, como a USP (www.revistas.usp.br), UFRN (www.periodicos.ufrn.br), UFSC (periodicos.ufsc.br), UFG (www.revistas.ufg.br), FURG (www.seer.furg.br), entre outras, mantêm portais institucionais de periódicos científicos utilizando o SEER, visando a apoiar boas práticas editoriais de suas publicações e a oferecer suporte à utilização institucional desta plataforma. No site temático do IBICT, é possível encontrar referências a pelo menos 129 portais brasileiros, com 12 revistas em média por portal e mais de 1000 revistas individualmente, todas usuárias do SEER.

A disponibilização eletrônica de revistas acadêmicas beneficia o livre acesso ao conhecimento, o que aumenta a visibilidade da revista e contribui para o avanço em direção à internacionalização da ABCS. Ao adotar e usar as potencialidades da internet, o SEER favorece a troca de conhecimento de forma ágil a um público cada vez maior e elimina as barreiras geográficas, gerenciando e organizado as informações acerca da revista e seus artigos e disponibilizando-os de forma padronizada aos interessados, sejam eles pesquisadores ou outros sistemas de informação. Ou seja, permite a geração automática de informações que podem ser exportadas para bases de dados, indexadores, agências de registro DOI (ex.: CrossRef) e mecanismos de busca especializados em conteúdo acadêmico (ex.: Google Scholar).

Dessa forma, a utilização de uma plataforma avançada é também um passo em direção aos grandes objetivos da ABCS Health Sciences, como a ampliação de sua indexação, a adoção de identificadores DOI para todos os seus artigos e a busca pelo aumento de visibilidade e maior impacto na comunidade nacional e internacional. Agora, vários aspectos das práticas editoriais serão realizados e gerenciados por meio da plataforma, o que trará maior agilidade e transparência ao processo editorial, desde a submissão de artigos pelos autores e o processo de avaliação cega pelos pares até a publicação dos artigos aprovados.

A implantação e, principalmente, a manutenção em longo prazo de sistemas dessa natureza, contudo, não são simples, e exigem conhecimento técnico especializado para que a plataforma opere correta e eficientemente. A manutenção estável e de qualidade ao longo do tempo de sistemas computacionais sofisticados como o SEER é um desafio conhecido pelos editores de periódicos no mundo inteiro. Uma alternativa atual para esse tipo de necessidade é a adoção de software como serviço, através da web, o que permite ao Corpo Editorial do periódico manter o foco nas atividades de sua competência e interesse, eliminando a necessidade de se preocupar com os desafios inerentes à área de Tecnologia da Informação (TI). Esta abordagem é conhecida popularmente como "nuvem", já que, para os utilizadores, não interessa o lugar específico onde estejam localizados, nem quantos ou quais são os equipamentos e softwares necessários para o funcionamento da plataforma.

A ABCS Health Sciences, em parceria com a Lepidus Tecnologia, optou por esta modalidade através do serviço Periódicos em Nuvens. Com esta solução, a partir desta edição a revista se encontrará “em nuvem”, e o Núcleo de Estudos, Pesquisa e Assessoria à Saúde (NEPAS) não precisará alocar equipamentos para instalação do SEER. Tampouco haverá a necessidade de uma equipe de TI interna para gerenciar a plataforma e os subsistemas dos quais ela depende (infraestrutura para envio de email, armazenamento de dados, servidor web etc.). 
O Periódicos em Nuvens oferece um ambiente SEER pronto para uso, com alguns recursos extras, além de uma série de facilidades para atender as necessidades de uma equipe editorial. Com isso, a ABCS Health Sciences tem garantia de estar acessível 24 horas por dia, sete dias por semana, com múltiplas cópias de segurança (backup) feitas diariamente, mantidas em locais geográficos distintos. A manutenção do sistema, a atualização de versões de software etc. serão feitas pela equipe especializada da Lepidus (bibliotecários, especialistas em TI, desenvolvedores de plugins que entendem as funcionalidades do SEER etc.), sendo que o processo será transparente aos usuários da revista, a qual continua integrada ao site da ABCS e em seu endereço eletrônico institucional.

Para o leitor que deseja saber mais sobre o SEER, o IBICT disponibiliza um espaço (http://seer.ibict.br/) para a comunidade brasileira de usuários contendo diversos documentos e informações sobre esta plataforma e seu uso. Além disso, a comunidade brasileira é ativa e receptiva, comunicando-se através de listas de discussões abertas organizadas por área geográfica e tema.

Esperamos que os leitores, autores, avaliadores, editores e todo o Corpo Editorial da ABCS Health Sciences aproveitem as potencialidades que o SEER oferece, e que esta nova etapa seja mais um passo de sucesso no aperfeiçoamento da revista. 